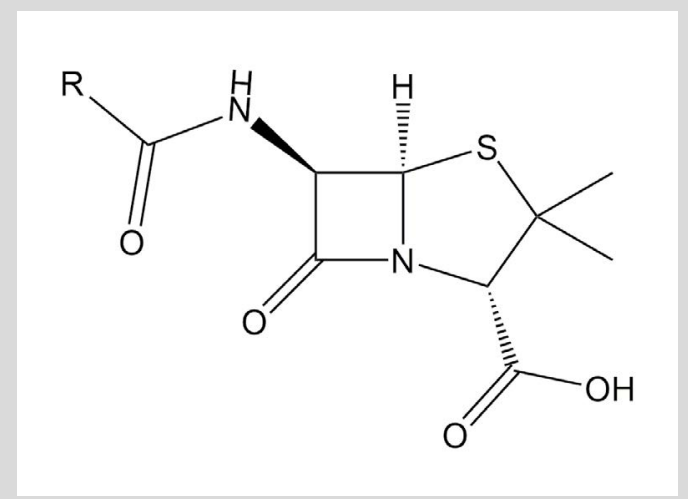

\title{
A Verdadeira História da Penicilina
}

Sérgio P. J. Rodrigues

spjrodrigues@ci.uc.pt
O "Projeto Penicilina" é muito menos conhecido do que o "Projeto Manhattan", mas durante a Segunda Guerra Mundial envolveu milhares de cientistas em centenas de laboratórios que procuraram um tratamento para as infeções. Este projeto dividiu-se em dois: conseguir produzir penicilina em quantidade, o que se conseguiu em 1943, e produzir penicilina de forma sintética, o que só se conseguiu em 1957, com o trabalho desenvolvido por John Sheehan (1915-1992). A história da penicilina parece ser muito bem conhecida, mas vale a pena recontá-la.

Em 1928, Alexander Fleming (1881-1955), médico que desde a Primeira Guerra Mundial procurava tratamentos para as infeções, encontrou por acaso um fungo que matava bactérias. Fleming não foi o primeiro a encontrar este efeito, mas foi o primeiro a pensar nisso como um medicamento - foi esta a sua maior descoberta. Costuma chamar-se a isso serendipidade. Infelizmente, não conseguiu isolar a penicilina. Isso só seria feito em 1941, por Howard Florey (1898-1968) e Ernst Chain (1906-1979), e as suas equipas. Mas nenhum dos dois grupos de investigação conseguiu produzir em quantidade a nova molécula. Para isso, concorreram as indústrias americanas, em particular a Pfizer, que desenvolveu o processo de fermentação profunda a partir dos trabalhos de Norman Heatley (1911-2004) e de Margaret Rousseau (1910-2000). Em 1943, iniciou-se a produção em massa. 0 prémio Nobel de Fisiologia ou Medicina veio em 1945 para Fleming, Flory e Chain. Entretanto, para fazer a síntese precisavam da estrutura molecular. E sabendo a estrutura, podem fazer-se modificações. A estrutura foi identificada em 1945 por Dorothy Hodgkin (1910-1994), que receberia o prémio Nobel da Química em 1964 pela determinação das estruturas de importantes substâncias bioquímicas usando técnicas de difração de raios $X$. A penicilina tem um anel pouco usual de quatro átomos e só em 1957 a equipa de John Sheehan desenvolveu a síntese total.

\section{Saiba mais em:}

J. C. Sheehan, The enchanted ring: The untold story of penicillin. Cambridge: MIT Press, 1984. ISBN-13: 978-0262690850.

S. P. J. Rodrigues, "A Química ao serviço da vida e prisioneira da guerra" em I. Abrantes, P. M. Callapez, G. P. Correia, E. Gomes, B. Lopes, F. C. Lopes, E. Pires, A. Rola (Eds.), Uma visão holística da Terra e do Espaço nas suas vertentes naturais e humanas. Homenagem à Professora Celeste Romualdo Gomes. Coimbra: CITEUC 2020. DOI: $10.5281 /$ Zenodo.4409383.

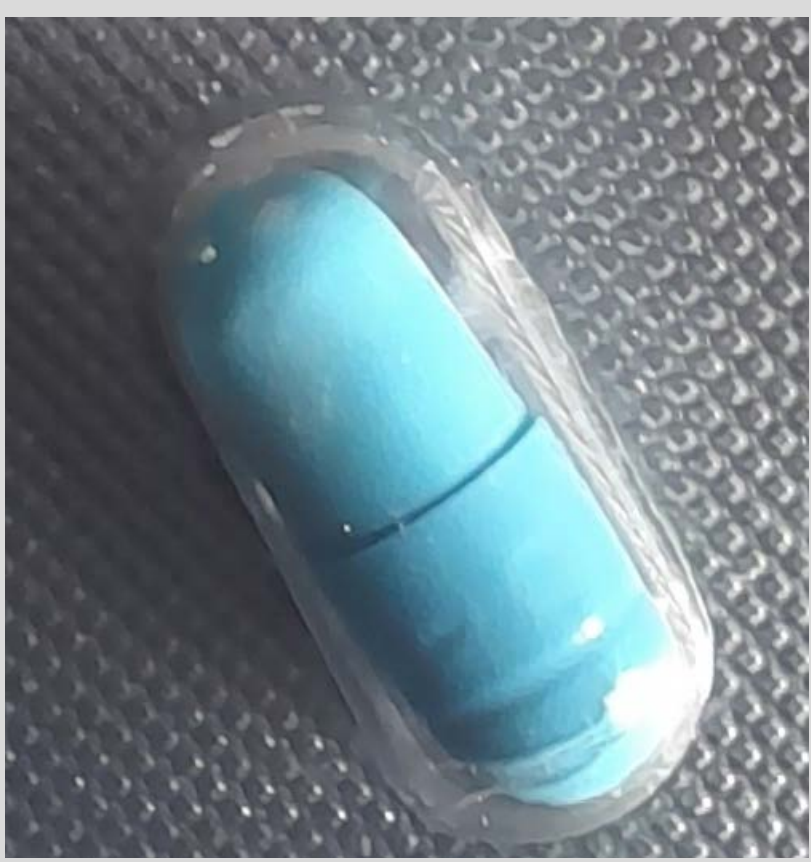

